\title{
A CASE STUDY OP THE P DEMOTION OPERATION
}

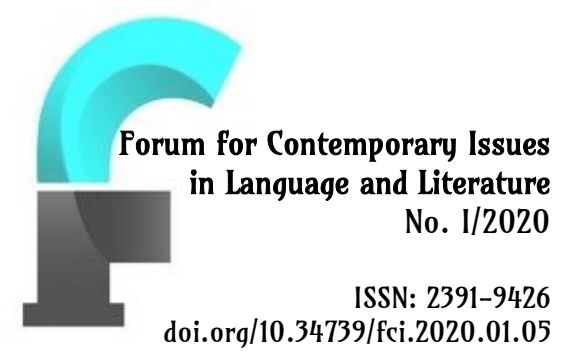

\author{
Katarzyna Janic \\ 0RCID: 0000-0003-3812-3287 \\ University of Leipzig \\ Faculty of Philology
}

\begin{abstract}
$P$ demotion is an umbrella term which refers to an operation performed on verbal valency. This mechanism results in a range of different constructions sharing two characteristics: the $P$ argument loses the properties of a core argument without affecting the semantic role of the $\mathrm{A}$ argument. This study examines a particular case of $\mathrm{P}$ demotion operation called antipassive. Until recently, the antipassive construction was regarded as the particularity of a morphologically ergative type of alignment, which, triggered by an explicit verbal marker, stands in a symmetrical relationship to the passive construction. These false beliefs blindly repeated for decades were, however, at the time well-justified. They resulted from the misinterpretation of the definition proposed by Silverstein $(1972,1976)$ and more importantly from the lack of adequate crosslinguistic data. However, a growing body of recent studies enables the questioning of the traditional view of the antipassive. It also provides new insights into the form and function of this construction as well as into language-specific and crosslinguistic variations. This contribution provides an overview of the most important issues involved in this particular type of the $\mathrm{P}$ demotion construction, with an attempt to explain the factors which could have biased its investigation.
\end{abstract}

Key words

P demotion operation, syntactic valency, incorporation, verbal marking, antipassive construction

\section{Introduction}

$\mathrm{P}$ demotion is a particular type of operation performed on verbal valency. It yields a number of grammatical constructions, including patient omission constructions, indefinite object constructions, antipassive, object incorporation, conative constructions, noun incorporation, differential object constructions, semitransitive and prepositional constructions (Heaton 2017,12). They all share one common characteristic, namely the $\mathrm{P}$ argument, which is coded like a patient of a core transitive verb, loses the properties of a core argument. This loss modifies the coding properties of this argument (such as flags and indexes as well as the behavior of this argument in a construction), without however, affecting the semantic role assigned to the $\mathrm{A}^{1}$. The $\mathrm{P}$ argument can be

\footnotetext{
${ }^{1} \mathrm{~A}$ is the argument which is coded like an agent of a core transitive verb.
} 
omitted, incorporated, or downgraded to an oblique position. In the literature there is no consensus on whether the aforementioned constructions illustrate distinct language phenomena or not. This question will not be pursued by the present study either. This work focuses specifically on the antipassive because of the considerable confusion which has arisen due to a complete misinterpretation of this notion.

The term 'antipassive' was first proposed by Silverstein $(1972,1976)$ and it refers to a specific type of grammatical construction that stands in a close relationship with the corresponding basic, transitive construction (Dixon 1994, 146; Polinsky 2005, 438; Heaton 2017, 6; Janic \& Witzlack-Makarevich 2021, \$1). It can be briefly defined as a construction which targets the $\mathrm{P}$ but not the A argument. The outcome of this operation is a syntactically intransitive construction in which the $\mathrm{P}$ argument loses the properties of a core argument, whilst the $\mathrm{A}$ argument functions as the $\mathrm{S}$ argument whose coding properties coincide with the coding properties of the core single argument of monovalent verbs. The common feature related to the antipassive construction is a verbal marker called the antipassive (Silverstein 1976, 140; Dixon 1994, 146; Palmer 1994, 178; Croft 2012, 333-334; Janic 2016, 50; Heaton 2017, 63). Traditionally, antipassive constructions are associated with languages with morphologically ergative alignment like Chukchi, in example (1).

(1) Chukchi (Chukotko-Kamchatkan; Kozinsky et al. 1988; Polinsky 2005, 438)
a. Paaček-a kimit?-ən ne-nl?etet-ən.
youth-ERG load-ABS 3PL.SBJ-carry-AOR.3SG.OBJ
'The young men carried away the load.'
b. ?aaček-ət ine-nl?etet-g?e-t kimit?-e. youth-ABS ANTIP-carry-AOR.3SG.SBJ-PL load-INS 'The young men carried away a load'.

In Chukchi, the antipassive construction (1b) is derived from the transitive construction involving two core A and P arguments, (1a). The construction carries the antipassive prefix ine-. As a result, the A argument (?aaček-ət 'youth-ABS') is now encoded as the single core argument of the verb associated with the absolutive form. The $\mathrm{P}$ argument (kimit?-e 'load-INS') is demoted to an oblique position. Its peripheral status is marked by the instrumental case -e. Additionally, in Chukchi, the transition to the antipassive construction modifies indexation on the verb. While in the transitive construction, both core arguments are coded on the verb, in the antipassive it is only the $\mathrm{A}$ argument that is indexed on the predicate.

A survey of the literature shows that the investigation of the antipassive construction has been biased for a very long time. For decades, this phenomenon has 
been associated only with morphologically predominantly ergative languages ${ }^{2}$ ( BokBennema 1991, 248; Cooreman 1994, 50; Palmer 1994, 197, etc.) with little or no regard for accusative languages. Another skewed direction concerns the antipassive marker. Silverstein's (1976) definition somehow suggests that the antipassive construction must obligatorily involve an explicit verbal marker (see Dixon 1994, 146), which is additionally limited to the antipassive function. This opinion goes against the recent work of Masullo (1992), Herslund (1997), Polinsky (2005, 438), Say (2008), Creissels (2006, 89), Medová (2009), Janic (2016), Heaton (2017), Mroczyńska (2018), Vigus (2018) and Zúñiga \& Kittilä (2019, \$3.2.2), who all convincingly show that the antipassive construction also exists in predominantly accusative languages. Moreover, if one assumes that the antipassive marker should be an obligatory criterion in the identification of a construction as antipassive, Polinsky (2005, 438), Janic (2016, 267, 2021, §2.1) and Creissels (2021, §4.2) show that some morphologically accusative languages have also a dedicated antipassive marker.

Inspired by Silverstein (1972, 1976), some scholars finally insisted on the mirrorimage relationship between passive and antipassive (Van Valin 1980; Polinsky 2005). That is, while in the standard passive it is the A argument that is demoted, in the antipassive it is the $\mathrm{P}$ that is demoted. Both operations may also involve a verbal marker. However, a more fine-grained analysis shows that the symmetrical relationship between passive and antipassive is less apparent and ultimately can be questioned (Lazard 1998, 229; Creissels 2006, 88).

Given that recent research has shed light on the new aspects of antipassive constructions, it is necessary to revise Silverstein's $(1972,1976)$ definition. Thus, one of the aims of this paper is to clarify in a metalanguage why the formulated concept of antipassive needs to be revisited. Since many recent studies identify the antipassive phenomenon based on structural criteria (but see Vigus 2018), another aim of this paper is to draw attention to the structural variation of the antipassive and to show how this construction displays it in languages.

This is an overview paper consisting of three parts. In the first part, I will provide a historical background of the notion of antipassive (Section 0). Then, I will approach three misleading trends resulting from Silverstein's definitions which have biased the investigation of antipassives. For this purpose, I will discuss the correlation of antipassives and alignment type (Section 0), the notion of the antipassive marker (Section 2.2) and the symmetrical relationship between antipassives and passives

\footnotetext{
${ }^{2}$ Following DeLancey (2004) and Creissels (2016), I also consider the term 'ergativity' to be heterogeneous and thus ambiguous, as it may refer to various aspects, including alignment, or the argument coding system e.g. case or agreement. In the present study, I will use the term 'ergative' with reference to an alignment pattern in case marking or indexation/agreement that treats $\mathrm{S}$ and $\mathrm{P}$ in the same way and A differently. Proceeding from this, I use the term 'ergative language' as a convenient shorthand for languages which exhibit ergative alignment in case marking and/or indexation. A similar logic applies to the terms 'accusative' and 'accusative languages'.
} 
(Section 0). In the final, third, part, I will address structural aspects of antipassives, briefly sketching out their morphosyntactic patterns (Section 0), as well as underlying forces which motivate the different realization of the P argument (Section 0). Section 4 offers a summary and concluding remarks

\section{The historical background of the antipassive notion}

The term 'antipassive' was introduced in the literature by Silverstein in (1972) with reference to a Chinook Jargon, a pidgin trade language spoken in the Pacific Northwest region. He defined it as a language-specific phenomenon, positing a formal and functional resemblance of the antipassive to its syntactic equivalent from accusative languages, i.e. the passive:

I have termed this -ki- form the ANTIPASSIVE construction, playing upon its inverse equivalence to a passive of accusative languages, because the sense is clearly equivalent to a transitive, though the form is intransitive, with the grammatical function of the remaining noun phrase reversed (ergator becomes non-ergator) (Silverstein 1972,395).

Even though the term 'antipassive' was thus introduced for the first time in 1972, it was not until four years later that it started to be recognized widely. Hence, it is not infrequent to find in the literature two dates, 1972 and 1976, which inaugurate the introduction of the antipassive term on the linguistic arena. In 1976, Silverstein published in Dixon his seminal article on 'Hierarchy of features and ergativity' with a slightly modified definition of the antipassive, which ultimately gained worldwide recognition. He defined the properties necessary to recognize the antipassive construction in ergative languages, featuring coding properties and antipassive marking in particular. In addition, he predefined the distribution of the antipassive structure:

Ergative systems have an analogous construction; here termed the antipassive (...). The 'unique' case here is the ergative, coding the unique function of direct transitive agent (A), and in antipassive forms the transitive agent is expressed by a surface absolutive (or nominative) case-marking, the verb has a change of voice, with a special mark, the transitive object (normally coded by surface absolutive case) appearing at most facultatively in some oblique, adverbial case-marking (Silverstein 1976, 140-142). 
Starting from 1976, the antipassive construction is thus no longer viewed as a languagespecific phenomenon of Chinook Jargon but as a crosslinguistic phenomenon, but limited to ergative languages.

Even though the term 'antipassive' appeared officially in the seventies, some authors argue that the phenomenon was already known earlier. According to de Rijk (2002), Russian researchers can be considered to be pioneers in the discovery of the antipassive construction. The author mentions that Russian scholars were aware of the presence of the antipassive already before the Second World War, while working on Avar, a Nakh-Daghestanian language spoken in the Caucasus and on some idioms from other Siberian languages. However, de Rijk (2002) does not provide details for his observation, limiting himself to this brief statement. If we consider the significant presence of antipassives in the Eskimo-Aleut family spoken inter alia in the territory of eastern Siberia and in other Nakh-Daghestanian languages (also called East Caucasian) (see Comrie et al. 2015 and Comrie et al. 2021), the speculations by de Rijk (2002) although intuitively based, are in fact highly justified.

A more documented support in favor of the claim that the antipassive was recognized much earlier than the official introduction of the term (i.e. Silverstein 1972) can be traced back to the Polish linguist, Jerzy Kuryłowicz. In his article "Ergativnost i stadialnost v jazyke" from 1946 that was translated into French three years later, the author already recognizes the antipassive, even though he does not employ any specific term to define it:

Concerning the transitive verbs, there are in the ergative system, just as in the nominative system, [several] possibilities (...). There is the ergative construction and, moreover, the absolute construction, that is a construction without a patient, which is lacking either because it is unknown or because it has no interest (...). As for the agent (...), it is in the absolute case (...). [Finally], there is the ergative construction (...), and next to it a diametrically opposed construction, marked from the stylistic point of view: agent to the absolute case, subjective verb, patient in the oblique case3 (Kuryłowicz 1949, 87).

The fact that the phenomenon of antipassive was recognized before Silverstein's (1972) publication is subsequently confirmed by Heath (1976). In his article 'Antipassivization, a functional typology', the author mentions very briefly that 'The term was suggested by Michael Silverstein, but the transformation has also been discussed under different names by Kuryłowicz, William Jacobsen, Dixon, and others' (Heath 1976, 202).

${ }^{3}$ My translation. 


\section{Misleading trends in the investigation of the antipassive}

Silverstein's $(1972,1976)$ definitions coupled with the fact that the author insisted on the structural resemblance of this construction to the passive in accusative languages, significantly shaped the landscape of the antipassive investigation across and within languages with far-reaching consequences that I will outline in §0-§0 accordingly.

\subsection{The correlation between alignment type and syntactic operations}

The fact that the term 'antipassive' was coined for a language with the morphologically ergative type of alignment had important consequences for the description of this phenomenon in individual languages and crosslinguistically because many linguists, e.g. Bok-Bennema (1991, 248), Cooreman (1994, 50), Palmer (1994, 197), Aldridge (2012, 193), etc., continued to associate this construction primarily with ergativity. This position was additionally strengthened by the fact that Silverstein's $(1972,1976)$ definitions insist on the structural resemblance of the antipassive construction to the passive in accusative languages.

Even if there is nothing in Silverstein's definitions that would openly exclude antipassives in accusative languages, scholars started to posit the existence of an implicational correlation between language-particular alignment types and specific syntactic operations, which, in a short time, began to be considered categorical. From the beginning, the passive construction was regarded as a particularity of languages with primarily nominative-accusative flagging and indexing coding patterns, while the antipassive construction was viewed as a hallmark of languages with traits of ergative alignment. As a result, the antipassive was extensively discussed in individual ergative languages (i.e. Mam [England 1983], Nez Perce [Rude 1988], Chamorro [Cooreman 1988], Warrungu [Tsunoda 1988], Chukchi [Kozinsky et al. 1988] etc.), or in ergative language groups (e.g. Kiranti [Bickel 2011], Tsezic [Comrie et al. 2015]; Circassian [Arkadiev \& Letuchiy 2021]), but not in accusative languages.

By contrast, the recognition of the passive construction in ergative languages has been acknowledged from the very beginning. Descriptions of Nez Perce from the Plateau Penutian family (Rude 1988), or the work on Halkomelem from a Salishan family (Gerdts 1988) or that on Mayan languages (England 1988), or still yet the papers by (Johns 1999, 2006) on Eskimo confirm this observation. However, unlike passive constructions, antipassives have not found an immediate place in the syntactic description of accusative languages.

A survey of the literature additionally reveals that there was a strong resistance among linguists to employ the term 'antipassive' in the description of accusative languages. Instead, a number of alternative terms have been coined to describe in these languages the morphosyntactic phenomenon, which closely resembles the standard antipassive of ergative languages. In Table 1, I present an overview of these terms (Janic 2016, 64-65). 
Table 1: Various terms defining the notion of antipassive in accusative languages

\begin{tabular}{|c|c|c|}
\hline Author & Term & Language \\
\hline Babby $(1975,322)$ & understood transitivity & Russian (Slavic group) \\
\hline Babby $(1975,323)$ & specified direct object & Russian (Slavic group) \\
\hline Schlie $(1983,25)$ & patient defocusing & Kara (Oceanic group) \\
\hline Brecht \& Levine $(1985,121)$ & agent attributives & Russian (Slavic group) \\
\hline Brecht \& Levine $(1985,122)$ & exclusive patient & Russian (Slavic group) \\
\hline Brecht \& Levine $(1985,123)$ & prioritized patient & Russian (Slavic group) \\
\hline Kański (1986, 142-143) & left-oriented middles & Russian (Slavic group) \\
\hline Geniušienè (1987, 94-97) & deaccusative subjective reflexive & Baltic group \\
\hline Geniušienè $(1987,256)$ & deaccusative reflexive & Romance and Slavic groups \\
\hline Geniušienė $(1987,318-319)$ & deaccusative reflexive & Turkic family \\
\hline Geniušienè $(1987,83-86)$ & absolute reflexive & Baltic group \\
\hline Geniušienè (1987, 249-251) & absolute reflexive & Slavic group \\
\hline Geniušienė $(1987,314-315)$ & absolute reflexive & Turkic family \\
\hline Lichtenberk (1991, 178-179) & Depatientive & Toqabaqita (Oceanic group) \\
\hline Davis $(2003,137)$ & Depatientive & Hoava (Oceanic group) \\
\hline $\operatorname{Bril}(2005,33)$ & Depatientive & $\begin{array}{l}\text { Xârâcùù, Drehu, Iaai } \\
\text { (Oceanic group) }\end{array}$ \\
\hline Noonan $(1992,125)$ & activity naming & Lango (Nilotic family) \\
\hline Ruzicka $(1992,157)$ & generic reflexive & Russian (Slavic group) \\
\hline Levin $(1993,39)$ & characteristic property of agent & English (Germanic group) \\
\hline Legendre \& Akimova $(1994,311)$ & excessive action & Russian (Slavic group) \\
\hline Legendre \& Akimova $(1994,311)$ & omitted object construction & Russian (Slavic group) \\
\hline Israeli $(1997,112)$ & aggressive action & Russian (Slavic group) \\
\hline Heath $(1999,166)$ & unspecified object & $\begin{array}{l}\text { Koyraboro Senni } \\
\text { (Songhay family) }\end{array}$ \\
\hline Tuggy $(2010,314-315)$ & unspecified object & Nahuatl (Uto-Aztecan) \\
\hline Liakin \& Ndayiragije $(2000,116-117)$ & inalienable possession & Russian (Slavic group) \\
\hline Rivero $(2000,18-19)$ & null object impersonal się & Polish (Slavic group) \\
\hline Rivero \& Sheppard (2003, 95-97) & accusative indefinites & $\begin{array}{l}\text { Polish, Slovenian } \\
\text { (Slavic group) }\end{array}$ \\
\hline $\begin{array}{l}\text { Haspelmath \& Müller-Bardey } \\
(2004,4)\end{array}$ & Deaccusative & $\begin{array}{l}\text { typological discussion } \\
\text { (e.g. Hungarian) }\end{array}$ \\
\hline $\begin{array}{l}\text { Haspelmath \& Müller-Bardey } \\
(2004,3)\end{array}$ & Deobjective & $\begin{array}{l}\text { typological discussion } \\
\text { (e.g. Ainu) }\end{array}$ \\
\hline $\begin{array}{l}\text { Haspelmath \& Müller-Bardey } \\
(2004,3)\end{array}$ & potential deobjective & $\begin{array}{l}\text { typological discussion } \\
\text { (e.g. Lithuanian, Udmurt) }\end{array}$ \\
\hline Nedjalkov (2006a, 18-19) & Absolutive & Turkic family \\
\hline Kuular $(2007,1214)$ & Ditransitive & Tuvan (Turkic family) \\
\hline
\end{tabular}


Some scholars even refrained from expressing their opinions on the correlation of antipassive with accusativity. In the chapter "Passive constructions in the world's languages" by Keenan \& Dryer (2007, 325-361), it remains unclear whether the authors consider this correlation to be exclusive: 'One further construction that resembles passive is antipassive generally found in ergative languages. While antipassives are typically associated with ergative languages, it is not uncommon for ergative languages to have passives'. Even if they do not reject the antipassive in accusative alignment, they do not admit its presence either.

However, an attenuation of the general attitude towards the rigid antipassiveergative correlation has recently taken place. See Polinsky (2005, 2017), Creissels (2006), Ndayiragije (2006), Say (2008), Medová (2009), Janic, (2016), Heaton (2017), Mroczyńska (2018), Vigus (2018) or the forthcoming volume on antipassives by Janic \& WitzlackMakarevich (2021b). A common agreement has developed that the relationship between antipassive-ergativity, on the one hand, and passive-antipassive, on the other, is gradient rather than categorical, as mismatches between different types of alignment and (anti-)passive constructions are encountered. A good example illustrating this point is Lezgian, a Nakh-Daghestanian language with the morphologically ergative type of alignment in which the antipassive phenomenon is not attested (Haspelmath 1993, 560). On closer examination, such correlations appear to be statistical tendencies at best. Even though some authors argue for the marginal existence of antipassives in accusative languages due to their lexical constraints (see the note by Ndayiragije 2006, 272), Creissels (2021) convincingly proves that this is not necessarily true for Soninke (Mande). Farrell $(2005,73)$ even goes one step further, postulating that 'languages often have both passive and antipassive voice constructions'. Naturally, their frequency varies from language to language. At the current stage of research, it stands as an undeniable fact that both alignment types may attest passives and antipassives. Example (2) shows the antipassive in French, an accusative language.

(2) French (Indo-European; Janic 2016, 205)

$\begin{array}{llllll}\text { a. Il } & \text { confesse } & \text { ses } & \text { péchés. } & \\ & \text { 3SG.M confess.3SG } & \text { 3PL.M.POSS } & \text { sin.PL.M } & \\ \text { 'He confesses his sins'. } & & & & \\ \text { b. Il se } \quad \text { confesse } & \text { de } & \text { ses } & \text { péchés. } \\ & \text { 3SG.M ANTIP confess.3SG } & \text { PREP } & \text { 3PL.M.POSS } & \text { sin.PL.M } \\ & \text { 'He confesses his sins'. }\end{array}$

Unlike in the transitive construction, (2a), the verb in the antipassive in (2b) carries the verbal marker se due to the presence of which $\mathrm{P}$ (ses péchés 'his sins') is demoted to an oblique argument. In French, the peripheral status of the latter is indicated by the preposition de. Similar to Chukchi in (1), in French, both transitive and antipassive 
constructions have the same event structure, which is conventionally indicated by identical or similar translations.

At this point, it is worth noticing that it is not only Silverstein's $(1972,1976)$ definitions that skewed the investigation of antipassive constructions towards ergative languages. Another reason for this results from the morphosyntactic properties of ergative languages which make the antipassive construction more visible there than in accusative constructions. In the former, the antipassive valency-reducing mechanism affects various aspects of the coding properties of the core arguments, including both flags (as we can spot new case markers on the arguments) and indexes that match the arguments on verbs. Additionally, the verb contains an antipassivizer (or 'antipassive marker'). By contrast, in accusative languages like French, the visibility of the antipassive construction is less apparent as the transition from a transitive to antipassive construction does not affect the coding of the A argument. In most cases, the indexation pattern also remains unchanged.

Finally, the exclusive antipassive-ergative correlation may also have a functional explanation. Building on the functions performed by the antipassive (see Vigus 2018, 343-346), it is legitimate to claim that both so-called ergative and accusative languages have antipassives driven by underlying semantic and/or pragmatic factors. This motivation for the antipassive use is strongly related to the parameter-assignment of semantic transitivity (Hopper \& Thompson 1980, 252), in particular to affectedness and individuation of the $P$ argument along with aspectual properties of the verb. Regardless of the type of alignment, any language has a means to indicate that the $\mathrm{P}$ argument is less individuated or less affected by the agent. See Cooreman (1994, \$2.1), Blight (2004, 113), Kulikov $(2011,396)$ on low individuation of the P argument, and Cooreman (1994, \$2.3) and Polinsky $(2017,329)$ on lower affectedness of the P argument. Therefore, in discussing the distribution of antipassives, it is important to consider the possibility that the semantic/pragmatic antipassive is independent of any type of alignment. In contrast, in languages with deep ergativity ${ }^{4}$ (cf. and only in this type of languages, the use of the antipassive construction can be motivated on a syntactic basis because only in this type of language is the absolutive the pivot for many grammatical operations, such as focalization, coordination, relativization (Dixon 2012, §23; Janic 2016, 281-284). It is therefore possible that in some ergative languages the antipassive assumes functions which have no equivalent in accusative languages, but this does not call into question the general claim that the antipassive-ergative and passive-accusative dichotomy is total.

\footnotetext{
4 'Deep ergativity' (e.g. Dyirbal, Pama-Nyungan, see Dixon 1972) refers to languages in which the A argument is not accessible to syntactic operations such as coordination, focalization, relativization, etc. The use of an antipassive construction in such languages enables the A argument to access these operations.
} 


\subsection{Overt antipassive marking}

Another misleading line of research resulting from the Silverstein definition involves the nature of the antipassivizer. Silverstein's (1976,140-142) formulation that 'the verb has a change of voice, with a special mark' is ambiguous. Consequently, it received different interpretations in the literature with far-reaching consequences. Some understood the term 'special' as 'specialized'. This can be observed in Polinsky (2005), who equates the term antipassivizer with the concept of dedicatedness:

The variation observed with respect to the marking of antipassives has to do with whether or not the language has a dedicated antipassive marker. A dedicated marker can often be associated diachronically with other functions (...), so what matters is its nonsyncretic synchronic status' (Polinsky 2005, 438).

Polinsky's (2005) account allows us to conclude that regardless of the diachronic origin, the antipassivizer is a fully specialized marker being limited to the antipassive function alone. Janic (2021, §2.2) notes a similar situation in Jacques (2021, §4.2). The author, who works on Rawang (Sino-Tibetan), reacts to LaPolla's $(2000,287)$ comments '[t]here are a number of constructions for increasing or reducing the valency of verbs in Rawang (Sino-Tibetan), but there is no passive or antipassive construction' in the following way:

Rawang shows a few examples of the use of the reflexive/middle -shì as an antipassive marker, when applied to transitive experiencer verbs (LaPolla 2000, 287 states that there are no antipassive constructions in Rawang, by which he probably means the absence of dedicated antipassive markers) (Jacques 2021, §4.2).

Yet some scholars approach the term 'special' in a broader sense, on a par with the term 'explicit'. This can be observed in Palmer (1994), who calls into question the existence of antipassives in accusative languages because of the lack of an explicit antipassivizer:

If a basic requirement is that [the antipassive] is explicitly marked (usually in the verb), it seems unlikely that there are, in fact, any languages with accusative systems (...) that also have antipassives (Palmer 1994,197).

The obscure formulation of 'special mark' influenced the line of research of scholars like Palmer (1994) and LaPolla (2000), who adopted the position that the antipassive obligatorily requires an explicit marker that by default must be a dedicated marker. Given that the term 'antipassive' was first introduced in so-called ergative languages, this presumably pushed many linguists to conclude that only such languages could 
have specialized antipassivizers. Although this opinion has never been explicitly pronounced, it somehow became textbook knowledge that dedicated antipassivizers are totally absent in accusative languages. This may explain why now, when antipassive constructions in languages with the morphologically accusative type of alignment are commonly recognized (Say 2008; Medová 2009; Janic, 2016; Heaton 2017; Vigus 2018, etc.), a growing interest is observed with regard to the specialized aspect of the antipassivizer in the aforementioned languages. This is particularly observed in the discussion by Nouguier-Voisin (2005) on Nahuatl (Uto-Aztecan), but also in Creissels (2021) on Soninke (Mande), in Renaudier (2012) on Sereer (Atlantic-Congo), and in Bostoen et al. (2015) on selected accusative languages from the Bantu group.

A good example of a predominantly accusative language with a dedicated antipassivizer comes from Soninke (Mande), where the functional motivation for the use of the antipassive construction is to be searched in the syntactic requirement to obligatorily express the $\mathrm{P}$ argument in transitive constructions. As reported by Creissels (2021), apart from a few exceptions, most transitive verbs in this language disallow their non-derived verbal forms to occur without an overtly expressed P. Such a restriction typically initiates a development of a new strategy that would enable bypassing this constraint. This is exactly what is observed in Soninke, which reserves the verbal suffix -ndi $\sim$ ndi for antipassive constructions, (3c).

(3) Soninke (Mande; Creissels 2012, 7)
people.PL-DEF TR millet-DEF cut
'The people harvested the millet'.
a. Sòró-n dà yillê-n pátá.
b. *Sòrô-n pátá.
people.PL-DEF cut
intended: 'The people harvested (the crops)'.
c. Sòrô-n pátá-ndì.
people.PL-DEF cut-ANTIP
'The people harvested (the crops)'.

Example (3a) shows a transitive construction whose underived verbal form pátá 'cut' occurs with two explicitly realized $A$ and $P$ arguments. The omission of the latter leads to ungrammaticality of the construction, as shown in (3b). The only possible way to bypass this constraint is to employ a dedicated antipassive marker-ndì, as shown in (3c).

Figure 1 shows the distribution of languages identified by Polinsky (2005) and Janic (2015) as having a dedicated antipassivizer. As shown, there is almost no difference in the number of accusative and ergative languages which attest the specialized antipassive marker. For an inventory of these languages and their genealogical affiliation see Tables 2-4. 


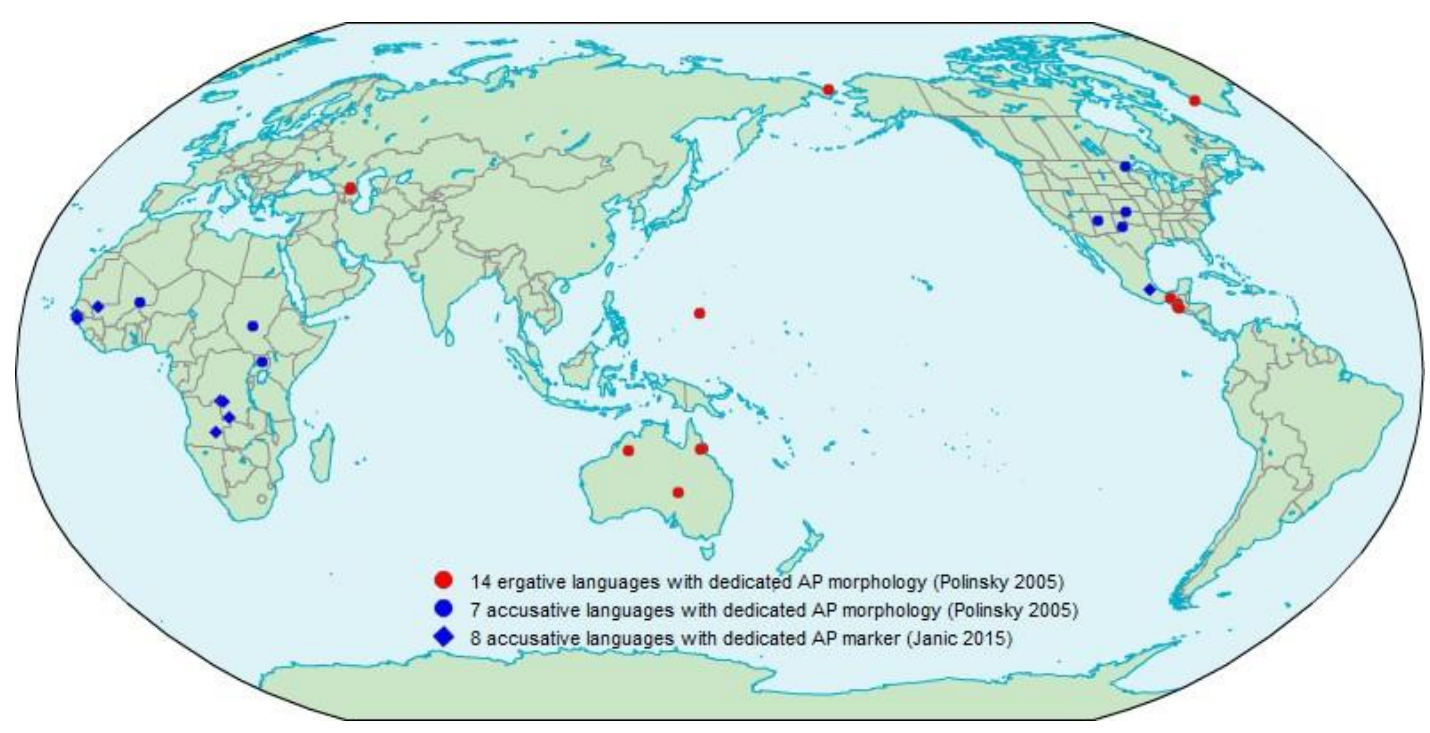

Fig. 1: Languages with dedicated antipassive morphology

Table 2: Ergative languages with dedicated antipassive morphology (Polinsky 2005)

\begin{tabular}{cc}
\hline Language & Family \\
\hline Chamorro & Austronesian \\
\hline Warrungu & Pama Nyungan \\
\hline Diyari & Pama Nyungan \\
\hline Dyirbal & Pama Nyungan \\
\hline Gooniyandi & Bunaban \\
\hline Hunzib & Nakh-Daghestanian \\
\hline West Greenlandic & Eskimo-Aleut \\
\hline Chukchi & Chukotko-Kamchatkan \\
\hline Godoberi & Nakh-Daghestanian \\
\hline Halkomelem & Salishan \\
\hline Jakaltek & Mayan \\
\hline Mam & Mayan \\
\hline Tzutujil & Mayan \\
\hline
\end{tabular}


Table 3: Accusative languages with dedicated antipassive morphology (Polinsky 2005)

\begin{tabular}{cc}
\hline Language & Family \\
\hline Acoma & Keresan \\
\hline Comanche & Uto-Aztecan \\
\hline Kiowa & Kiowa-Tanoan \\
\hline Ojibwe & Algic \\
Koyraboro Senni [sic] & Songhay \\
\hline Krongo & Kadu \\
\hline Lango & Eastern Sudanic \\
\hline
\end{tabular}

Table 4: Accusative languages with dedicated antipassive morphology (Janic 2015)

\begin{tabular}{ccc}
\hline Language & Genus & Family \\
\hline Nahuatl & Aztecan & Uto-Aztecan \\
\hline Soninke & Western Mande & Mande \\
\hline Mandinka & Western Mande & Mande \\
\hline Balanta & Northern Atlantic & Niger-Congo \\
\hline Kete & Bantoid & Niger-Congo \\
\hline Songe & Bantoid & Niger-Congo \\
\hline Lucazi & Bantoid & Niger-Congo \\
\hline Lunda & Bantoid & Niger-Congo \\
\hline
\end{tabular}

In her typological study on antipassive constructions, Heaton $(2017,2002)$ advances the investigation of dedicated antipassivizers. In contrast to Polinsky $(2017,14)$, the author argues that such markers are not crosslinguistically rare. Approximately $32 \%$ of the languages from Heaton's sample are recognized as having a dedicated antipassive marker.

The recent studies on the antipassive marker have revealed that some languages may have even more than one dedicated antipassivizer (Janic 2021, §2.2; (Janic \& Witzlack-Makarevich 2021a, §4.2). Jacques (2014), Sansò (2017), Mithun (2021) and Say (2021) convincingly show that the existence of the multiple dedicated antipassivizers is driven by the animacy properties of the $\mathrm{P}$. In some languages, the antipassive maker targets not only the $\mathrm{P}$ argument but also animacy features it displays. For instance, Comanche (Uto-Aztecan) has two antipassive prefixes, $m A$ and $t i$, specialized for demotion of the human and non-human P argument respectively (Charney 1993, 128129). Japhug (Sino-Tibetan; Jacques 2014, 10) also has two antipassive prefixes, $r \gamma$ - and $s \gamma$, which are employed to eliminate a non-human and human $\mathrm{P}$ argument respectively. Launey $(1994,48)$ and Pustet \& Rood $(2008,342-345)$ report a comparable situation in Nahuatl (Uto-Aztecan) and in Lakota (Siouan) respectively. 


\subsection{The antipassive as a mirror image of the passive construction}

Another misleading interpretation resulting from Silverstein's $(1972,1976)$ definitions concerns the allegedly symmetrical relationship between passive and antipassive. Polinsky $(2005,438)$ notes that ' $[t]$ he term antipassive (...) was coined to indicate that the construction is a mirror image of the passive.' At the coarse-grained level, this observation is justified because the standard passive demotes the A argument, whilst in the antipassive it is the $\mathrm{P}$ that undergoes syntactic degradation. However, such an approach is somewhat simplistic as it focusses only on one specific aspect of these two types of valency operations, i.e. demotion of the core argument. At a more fine-grained level, these two types of valency-reducing operations turn out to display formal and functional differences, which calls into question the purported symmetrical relationship between antipassive and passive constructions.

In the first place, the lack of symmetry manifests itself at the functional level and concerns the relationship holding between semantic and discursive roles of arguments (Creissels 2006, 89). If in a prototypical transitive construction at the discoursepragmatic level, the agent (or A argument) is viewed as the most topical or as the most 'salient', whilst the patient (or P argument) is regarded as less topical, then the passive construction entirely modifies the initial linking between semantic and discourse roles associated with these arguments. This is because the promotion of the $\mathrm{P}$ to the subject function topicalizes this argument. Consequently, it receives the most salient interpretation. Nothing comparable happens to the antipassive. The latter does not affect the discourse-semantic relationship of the arguments. It only modifies their degree of topicality: while topicality of the agent is reinforced, one of the patient arguments is reduced because of the move to the peripheral status.

There are also formal differences between antipassives and passives. Creissels $(2006,88)$ mentions two such key differences. The first one involves promotion. Promotion can be defined as a syntactic mechanism that recognizes as core argument, an argument which otherwise could not carry this status. Promotion may also refer to a mechanism which treats as a subject an argument which otherwise would be viewed as an object (Creissels 2006, 8). Given the above, the formal contrast between standard passives and antipassives becomes visible. Unlike the canonical passive which entails both demotion (of $\mathrm{A}$ ) and promotion (of P) mechanisms (Dixon 2012, 206), the standard antipassive does not involve any promotion (Dixon 2012, 208), because building on Creissels $(2006,8)$, the subject argument is not available to any syntactic promotion in the antipassive. Another variation concerns the syntactic transitivity of the verbs. In contrast to antipassives, passives are not constrained to transitive verbs, as they are also compatible with intransitive predicates. Many languages such as Dutch, Turkish, Slavic, Latin, etc. attest impersonal passives, derived from the intransitive verbs (see various literature on this topic, including Comrie 1977; Dixon \& Aikhenvald 1997; Blevins 2003). 
At this point, it is worth noting recent findings from Circassian languages (Arkadiev \& Letuchiy 2021). The authors, who operate with the notion of extended intransitive clause type (Dixon \& Aikhenvald 2000,3) show that in some of these languages, the antipassive can be derived from bivalent intransitive verbs with $S$ and E (extended) arguments, as shown in (4).

(4) Kuban Kabardian (Circassian; Arkadiev \& Letuchiy 2021, \$3.1)
a. se ŝ.ale-m s-je-? ${ }^{\text {w } ə \text { ns }}$.ə-ne.
1SG boy-OBL 1SG.ABS-DAT-push-FUT
'I will shove that boy'.
b. sabəj-xe-r me-? ${ }^{w} ə$ nŝ.e
child-PL-ABS DYN-push.ANTIP
'The children are jostling'.

Example (4a) shows an intransitive active use of the bivalent verb 'push' which selects the absolutive pronominal argument se 'I' and the extended nominal argument s. ale-m 'boy'. The latter functions as a peripheral argument which is indicated by the oblique case $-m$. It is additionally indexed on the verb by the dative prefix je. Example (4b) is the derived construction which is also syntactically intransitive. It meets the formal criteria for antipassives. The non-agent argument is eliminated from the surface structure and the predicate is overtly marked by the modification of the verbal stem from /ə/ into /e/. The obligatory omission of the extended argument is motivated at the discourse level. It is eliminated because it is considered to be irrelevant.

Data from Circassian are particularly interesting. On the one hand, (4b) should be excluded from the antipassive investigation as its input verb does not meet the definitional criteria. Recall that antipassives exist only in relationship to corresponding transitive constructions. On the other hand, the overall characteristics of the construction allow us to approach (4b) as an example of the antipassive both at the functional and formal level. A potential solution to this impasse is the reformulation of the antipassive definition, which in order to include the Circassian data, should operate in terms of verbal valency referring to the number of arguments the verb occurs with, rather than in terms of syntactic transitivity of the verb.

\section{The formal and functional diversity of antipassive constructions}

The antipassive has been mainly investigated from a structural perspective (Foley \& Van Valin 1984,168-181; Dixon \& Aikhenvald 2000, 7; Foley 2007, 429; Shibatani 2009, 326; Zúñiga \& Kittilä 2019, 103). A quick survey of the literature reveals both that this construction displays a whole range of morphosyntactic variations, and that there are disagreements between scholars how to approach these variations. The aim of this 
section is to signal and briefly describe in the metalanguage of comparative research the scope of these variations. Section 0 deals with various parameters of variations such as coding properties, different $P$ realizations and variations related to antipassive marking, whilst section 0 discusses the motivation for different behavior of the $\mathrm{P}$ argument.

\subsection{Parameters of variations}

In languages with the morphologically ergative type of alignment, the transition from basic, transitive constructions to antipassives frequently entails a change in flagging of the A argument from ergative to absolutive (but see ex. (6)). Yet, in others, this shift may additionally modify indexes matching the arguments on the verb. Example (5b) from Baffin Island illustrates the antipassive construction in which the non-core status of the $\mathrm{P}$ argument is signalled by the oblique -mik case, in addition to the change of the indexation pattern.

(5) Baffin Island (Eskimo-Aleut, Inuktitut; Spreng 2005, 216)
a. Anguti-up arnaq kunik-taa.
man-ERG woman kiss-3SG.3SG
'The man kissed the woman'.
b. Anguti kunik-si-vuq arna-mik.
man.ABS kiss-ANTIP-3SG woman-OBL
'The man is kissing a woman'.

Even if in many ergative languages, a transition from ergative to antipassive constructions frequently involves a change in coding properties of the A argument from ergative to absolutive, as in (5), some languages deviate from this pattern. Polinsky $(2017,5)$ reports at least three languages in which the A argument preserves the ergative case in the antipassive construction: Warlpiri (Pama Nyungan; Hale 1973, 366) illustrated in (6), Jaru (Pama Nyungan; Tsunoda 1981, 149) and Gooniyandi (Bunaban; Tsunoda 1988, 627).

(6) Warlpiri (Pama Nyungan; Hale 1973,366)
a. Njuntulu-lu npa-tju pantu-nu 3SG-ERG 2SG-1SG spear-PST
natju. 'You speared me'.
b. Njuntulu-lu npa-tju-la 3SG-ERG 2SG-1SG-ANTIP 'You speared at me'. pantu-nu natju-ku. spear-PST 1SG-DAT 
The realization of the $\mathrm{P}$ argument constitutes another parameter of variation (Vigus 2018, 358-368; Zúñiga \& Kittilä 2019, \$2.4.1; Polinsky 2017, 3; Janic \& Witzlack-Makarevich 2021, \$3, etc.). Linguists typically mention two types of behavior. While some languages can express the $P$ argument explicitly as an oblique, as in (7b)-(8b), others impose a constraint on it, blocking this argument from overt expression, as in (9c).

(7) Kuku Yalanji (Pama Nyungan; Patz 2002, 152)
a. Nyulu dingkar-angka minya nuka-ny.
3SG.NOM man-ERG meat.ABS eat-PST
'The man ate meat'.
b. Nyulu dingkar minyA nga nuka-ji-ny.
3SG.NOM man.ABS meat-LOC eat-ANTIP-PST
'The man had a good feed of meat (he wasted nothing)'.

(8) Spanish (Indo-European; Mejias-Bikandi 1999,174)
a. Pedro olvidó los libros.
Peter forgot DEF books
'Peter forgot the books.'
b. Pedro se olvidó de los libros.
Peter ANTIP forgot PREP DEF books
'Peter forgot the books'.

(9) Polish (Indo-European; Janic 2016, 148)
a. Wasz
syn
bije
dzieci.
2PL.POSS
son.NOM
beat.3SG.PRS
children.ACC

'Your son is beating up the children'.
b. Wasz syn bije się.

2PL.POSS son.NOM beat.3SG.PRS ANTIP

'Your son is beating up [children]'.
c. ${ }^{*}$ Wasz syn bije się dzieci.
2PL.POSS son.NOM beat.3SG.PRS ANTIP children.ACC
'Your son is beating up the childre'.

While Dixon \& Aikhenvald $(2000,9)$ underline the optionality of the oblique argument in the antipassive construction, Janic \& Witzlack-Makarevich (2021a, \$3) note the instances in which this argument must be obligatorily realized. Examples from French in (10) illustrate this point. This may result from the lexical properties of the verbal predicate. 
(10) French (Indo-European; Janic 2016, 205)

a. Les étudiants attaquent les révisions dès DEF.PL student.PL start.PRS.3PL DEF.PL revision.PL PREP le mois de mars. DEF.SG.M month PREP March 'The students start the revision from March'.

b. Les étudiants s' attaquent aux révisions DEF.PL student.PL ANTIP start.PRS.3PL PREP.DEF.PL revision.PL dès le mois de mars. PREP DEF.SG.M month PREP March 'The students start the revision from March'.

c. *Les étudiants $\mathrm{s}$ ' attaquent dès le mois de mars. DEF.PL student.PL ANTIP start.PRS.3PL PREP DEF.SG.M month PREP March 'The students start the revision from March'.

Finally, Givón (2001, 36), Vigus (2018, 360) and Zúñiga \& Kittilä (2019, 206) consider incorporation to be another type of variation of the $\mathrm{P}$ argument behavior in the antipassive, regardless of whether incorporation is triggered by an antipassive marker or not, as in (11b).

(11) Boumaa Fijian (Austronesian; Dixon 1988, 49)

3SG.SBJ eat-TR DEF taro

Yet for others, the inclusion of $\mathrm{P}$ incorporation in the antipassive is regulated by the presence of the antipassive marker. Foley \& Van Valin (1984, 343) consider incorporation as a particular case of the antipassive because both types of construction can be derived by the same affix. Data from the Oceanic family support this observation. In Hoava, vari- can trigger both incorporation and antipassivization, as shown in (12a) and (12b) respectively. 
(12) Hoava (Austronesian; Davis 2003,137-138)
huke,
ninami
vari-nahu
tia.
ART taro.leaf food DEP5-hurt
stomach

'Taro leaves, food (which) can hurt stomachs'.

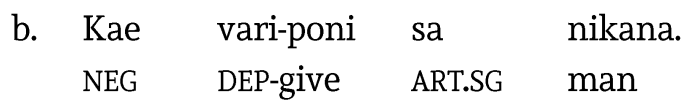

'The man is selfish.' lit. 'The man does not give to [anyone]'.

Incorporation shown in (11b) and (12a) is syntactic in nature, because the $\mathrm{P}$ argument is not morphologically bound to the verb but only juxtaposed to it. Mithun (1984), who analyses a similar case in Tongan (Oceanic) notes that although noun and verb remain separate at the phonological level, they form a compound in which the $P$ is rigid in terms of mobility and incompatible with determiners. Mayan languages can also serve as another illustration of languages with the morphological overlap between antipassive and P incorporation. Yucatec (Bricker 1978), Mam (England 1983, 110) and Jakaltek (Grinevald-Craig 1979, 7-9) are some of them (see Heaton 2017 for a detailed discussion of this issue in Mayan languages).

However, in contrast to the oblique realization and the omission of the $\mathrm{P}$, the submission of the incorporated $\mathrm{P}$ argument under the domain of antipassive construction has not achieved consensus among the scholars. This is observed by Foley $(2007,435)$, who argues that '[object incorporation does] not illustrate true antipassives, as there is no requisite derivational morphology for antipassivization in the verb or verbal complex' in languages with both antipassive and incorporation. To support his claim, the author builds on the language-specific analysis of Chukchi, in which it is only the antipassive construction, (1) repeated here as (13), but not incorporation, (14b), which takes the antipassivizer on the verb.

(13) Chukchi (Chukotko-Kamchatkan; Polinsky 2005, 438)
a. Paaček-a kimit?-ən ne-nl? etet-ən. youth-ERG load-ABS 3PL.SBJ-carry-AOR.3SG.OBJ '(The) young men carried away the load'.
b. Paaček-ət ine-nl?etet-g?e-t kimit?-e. youth-ABS.PL ANTIP-carry-AOR.3SG.SBJ-PL load-INS '(The) young men carried away a load'.

\footnotetext{
${ }^{5}$ Davis $(2003,135)$ glosses the prefix vari- as depatientive. In Janic (2018, 166-167), this affix is analysed as performing the antipassive function.
} 
(14) Chukchi (Chukotko-Kamchatkan; Comrie 1978; Foley 2007,437)
a. Tumg-e n-antəwat-ən kupre-n.
friend-ERG 3PL.ERG-set-3SG.ABS.AOR net-ABS
'The friends set the net'.
b. Tumg-ət kupr-antəwat-g?at.
friend-ABS.PL net-set-3PL.ABS.AOR
'The friends were net-setting'.

Apart from the lack of antipassive morphology, incorporation is structurally similar to the antipassive as both target the $\mathrm{P}$ argument. In (14b), the $\mathrm{P}$ 'net' no longer functions as a core argument of the verb 'set'. It is morphologically incorporated into the predicate and constrained in terms of mobility. In the antipassive, (13b), the $P$ argument 'load' is demoted to an oblique. The peripheral status of this argument is indicated by the instrumental case -e. Incorporation and antipassive also modify in like manner flags of the A argument and indexes on the verb. The A argument is absolutive and this is the only core argument which is marked on the verb. Incorporation and antipassives also display functional similarities as in both instances the $\mathrm{P}$ argument displays a reduced degree of identifiability (Foley 2007, 437).

Since the borderline between incorporation and antipassives is not apparent (Malchukov 2015, 98) the question arises as to whether they should be taken as distinct phenomena or not. Linguists frequently do not provide a clear answer, limiting their investigation to pointing out similarities and differences displayed by incorporation and antipassives (e.g. (Creissels 2021, §6 and Moyse-Faurie 2021, §3). However some do adopt a clear position by providing arguments against treating both types of constructions as the same language phenomenon. For instance, Foley (2007) takes the antipassivizer as a formal indicator distinguishing these two types of construction. However, data from Hoava flatly contradict Foley's (2007) observation. A more convincing line of argumentation coming from Creissels $(2006,15)$ is related to the ability of a verb to assign a patient role to a noun phrase. According to the author, the nominal that is incorporated into a verb 'absorbs' the semantic role assigned to it by the verb. Consequently, the predicate is unable to take another NP to which it could assign the absorbed semantic role. By contrast, nothing similar can be argued for antipassives.

Another noticeable parameter of variation concerns the nature of the extra morphological material on the verb. Janic (2021, §2.1) signals that the antipassivizer may be dedicated (e.g. the antipassive marker -ndì -ndí in Soninke, Creissels 2021, $\S 4.2)$ or co-expressive. A text-book example is the se marker from Indo-European languages. For example, in Russian, the -sja suffix is involved in numerous valencyreducing operations such as anticausative (15a), reflexive (15b), reciprocal (15c), antipassive, (15d), passive (15e), and impersonal (15f). 
(15) Russian (Indo-European; Malchukov 2017, 7-8; Geniušienė 1987, 285)
a. Palka slomala-sj.
stick.SG.NOM break.PST.3SG-SJA
'The stick broke.'
b. On moet-sja.
he wash.PRS.3SG-SJA
'He washes.'
c. Oni vstretili-sj.
they met.PST.3PL-SJA
'They met.'
d. Sobaka kusaet-sja.
dog.SG.NOM bite.PRS.3SG-SJA
'The dog bites.'
e. Dom stroit-sja rabochimi. house.SG.NOM build.PRS.3SG-SJA worker.PL.INS 'The house is (being) built by the workers.'
f. $\mathrm{Ob}$ et-om soobs`c`ajet-sja v gazet-ax. about this-PREP reports-SJA in newspaper-LOC.PL
'This is reported in newspapers.'

A final parameter of variation concerns the nature of antipassive marking. In a few languages, the change of valency is not signalled by an overt marker, but by the phonological change in the verbal stem. For instance, in Circassian languages, the antipassive verb is built from the verb whose stem ending in /ə/ is replaced by /e/ (Arkadiev \& Letuchiy 2021, \$3.1). Zúñiga \& Kittilä $(2019,113)$ report a similar situation in Dinka (Nilotic). Example (16) shows a contrast in the verbal stem with the creaky vowel which is reserved for active, transitive verbs, (16a), and the verbal stem with the breathy vowel employed in the antipassive construction, (16b).

(16) Dinka (Nilotic; Schröder 2015, 55)
a. Petero a-pil bël.
Petero 3SG.INCOMPL-strip.ACT cane
'Peter is stripping the cane'.
b. Petero a-pil.
Petero 3SG.INCOMPL-strip.ANTIP
'Peter is stripping'.


Unlike morphological variations of flagging and indexation along with various syntactic behaviour of the $\mathrm{P}$ argument, diversity resulting from antipassive marking is definitional rather than empirical in nature. There is disagreement between scholars of whether the antipassivizer should be viewed as an obligatory criterion in the recognition of the antipassive phenomenon (Mroczyńska 2019, 200; Janic 2021, §4, Seržant et al. 2021). The recent data from Circassian and Nilotic languages additionally show that antipassive marking may not necessarily involve extra morphological material on the verb. Among those who maintain the position that the antipassive should contain an antipassivizer, there are also scholars like Blight (2004) and Mroczyńska $(2017,2018)$ who find that this criterion may not be sufficient to correctly identify the antipassive. Both authors convincingly show that languages like English may have constructions that are functionally comparable to marked antipassives. Even if this is a perfectly legitimate approach based on a language-particular investigation, it is generally problematic in languages like English which display the morphologically accusative type of alignment and in which a decrease in valency is signalled neither by a change of the coding of the A argument nor by a change in indexation. In such languages, pairs like He often reads the book vs. He often reads or Speed kills peoplevs. Speed kills pose an empirical challenge because they do not have morphosyntactic indication showing whether they should be approached as a particular type of transitivity alternation or as null object constructions (known also in the literature as 'A preserving-lability' or 'ambitransitivity'). In contrast to the antipassive, a null object construction can be analysed as involving a transitive verb which admits a null object with an unspecific reading (Creissels 2015, 225). See Mroczyńska $(2019,197-199)$ on various types of null object in English.

\subsection{Motivations for different realizations of the $P$ argument}

The motivation behind the different realization of the $\mathrm{P}$ argument in antipassive constructions varies crosslinguistically. It may be language specific related to external discourse properties of the $\mathrm{P}$ argument ${ }^{6}$ or to the process of lexicalization. In what follows, I will briefly discuss the motivation for different behavior of the $\mathrm{P}$ argument in antipassive constructions.

In Mam (Mayan), the realization of the $P$ can be motivated by discourse properties. Among various types of antipassive constructions (e.g. syntactic, incorporative, lexical), Mam has also absolutive antipassives in which the expression of the $\mathrm{P}$ is blocked. This happens when the P referent is not identifiable ${ }^{7}$ in the discourse context because it was not mentioned previously or because it is unknown to the hearer (England 1983, 214), as shown in (17b).

\footnotetext{
${ }^{6}$ In languages with deep ergativity, antipassive constructions may also display syntactic functions. However, these functions are beyond of the scope of the present study.

7 The term 'identifiability' is understood as 'a speaker's assessment of whether a discourse representation of a particular referent is already stored in the hearer's mind or not' (Lambrecht 1994, 76).
} 
(17) Mam (Mayan; England 1983, 214; Cooreman 1994, 53)
a. Ma Ø-w-aq'na-7n-a.
ASP ABS.3SG-ERG.1SG-work-DS-1SG
'I worked it (something)'.
b. Ma chin aq'naa-n-a.
ASP ABS.1SG work-ANTIP-1SG
'I worked (no implication of what was worked)'.

Example (18) illustrates another case of the antipassive with the suppressed $\mathrm{P}$ argument.

(18) Russian (Indo-European; Babby 1975, 322)
a. Naša
sobaka ne
kusaet
detej.
Our.SG.F.NOM dog.SG.F.NOM NEG
bite.3SG.PRS
child.PL.ACC
'Our dog does not bite children'.
b. Naša
sobaka
ne
Our.SG.F.NOM dog.SG.F.NOM NEG
'Our dog does not bite'.
kusaet-sja.
bite.3SG.PRS-ANTIP

The motivation to constrain the realization of the P in Russian in (18b) is different compared to Mam (17b). Only predicates which express antisocial or antagonistic actions such as 'bite', 'push', 'nickname', etc. can occur in Russian antipassives with the syntactically supressed $\mathrm{P}$ argument. This is because the antipassive in (18b) is triggered by the reflexive marker -sja and the syntactic structure of the resulting construction overlaps with the truly reflexive constructions also schematized as $\left[\mathrm{NP}_{\mathrm{s}}+\right.$ verb-sja]. Given that the primary function of a reflexive morpheme is to indicate that the agent, instead of acting on the patient, acts on him/herself, the implementation of antisocial or antagonistic verbs into a reflexive structure $\left[\mathrm{NP}_{\mathrm{s}}+\right.$ verb-sja] forces the hearer to reinterpret such a construction as the antipassive, where the verb denotes a semantically transitive action with the agent acting on a distinct participant. This reanalysis is pragmatically motivated, because it is more plausible and natural that the agent, who performs the antagonistic action with detrimental effects, will do it on a distinct participant rather than on him/herself. This pragmatic motivation cancels the co-referential function otherwise performed by a reflexive marker. So-called absolutive antipassives with antisocial or antagonistic verbs are typical of Slavic languages (Janic 2016, 154-155).

In some languages, low degree of identifiability of the $P$ does not necessarily lead to the suppression of this argument. In this respect, Chamorro (Austronesian) shown in (19) differs from Mam, (17). In this language, the low individuated $\mathrm{P}$ with an indefinite or generic interpretation can be overtly expressed as an oblique. Example (19b) illustrates this point. 
(19) Chamorro (Austronesian; Cooreman 1988, 571; Cooreman 1994,54)
a. Ha-konne' i peskadot i guihan. ERG.3SG-catch the fisherman the fish
'The fisherman caught the fish'.

b. Mangonne' (guihan) i peskadot.

'The fisherman caught fish /a fish (something)'.

A similar observation holds in Kuku Yalanji (Pama Nyungan). As reported by Vigus (2018, 367), this language uses the basic, transitive construction when the action denoted by a verb is performed on a highly specific $P$ argument (Patz 2002,152). When this criterion is not satisfied, Kuku Yalanji employs an antipassive in which a $\mathrm{P}$ argument that is obligatorily expressed as an oblique is conceived as less individuated. This contrast is shown in (20).

(20) Kuku Yalanji (Pama Nyungan; Patz 2002,152)
a. nyulu dingkar-angka minya
nuka-ny. 3SG.NOM man-ERG
meat.ABS
eat-PST
'The man ate meat'.
b. nyulu dingkar minyA nga nuka-ji-ny. 3SG.NOM man.ABS meat-LOC eat-ITR-PST
'The man had a good feed of meat (he wasted nothing)'.

The employment of the antipassive can also be related to the affectedness of the $\mathrm{P}$ argument. In some languages this construction is used when the $\mathrm{P}$ is not entirely affected. A text-book example comes from English, in which conative alternations such as Margaret cut the bread. vs. Margaret cut at the bread (Levin 1993, 6) have comparable interpretative effects as antipassives as shown in (21) and (22). See also Cooreman (1994, 58-62), Polinsky (2017, \$13.7), Vigus (2018, 344), Zúñiga \& Kittilä $(2019,112)$ and Janic \& Witzlack-Makarevich (2021a, \$5.1) on affectedness of the $\mathrm{P}$ argument in the antipassive construction.

(21) Chamorro (Austronesian; Cooreman 1994, 59)
a. Un-patek i ga'lago. ERG.2SG-kick the dog 'You (sg) kicked the dog'.
b. Mamatek hao gi ga'lago. ANTIP.kick 2SG.ABS LOC dog 'You (sg) kicked at the dog'.


(22) Chukchi (Chukotko-Kamchatkan; Kozinsky et al. 1988, 652)
a. ətləg-e keyn-ən penrə-nen.
father-ERG bear-ABS attack-3SG:3SG.AOR
'Father attacked the bear'.
b. ətləg-ən penrə-tko-g?e kayn-etə.
father-ABS attack-ANTIP 3SG.AOR bear-DAT
'Father rushed at the bear'.

A particularly interesting example comes from East Uvean (Austronesian) in (23), in which the $\mathrm{P}$ argument expressed as an oblique does not signal that it is partially affected but that it is specifically and exclusively affected. This is rather crosslinguistically unexpected.

(23) East Uvean (Austronesian; Moyse-Faurie 2021, §4.1)
a. Vaka’i ia te pāsina faka’osí! examine ABS SPC page last
'Examine the last page!'
b. Vaka’i ki te pāsina faka’osí! examine OBL SPC page last
'Examine specifically the last page'.

The antipassive illustrated in (23b), does not contain an explicit verbal marker. However, the general characteristics of this construction meet the definition of the antipassive: the $\mathrm{P}$ argument is moved to a peripheral status, which is signalled by the oblique marker ki. Yet examples (2) and (10), repeated here for convenience as (24) and (25) respectively, illustrate another motivation for the different behaviour of the $\mathrm{P}$ argument in the antipassive.

(24) French (Indo-European; Janic 2016, 205)
a. Il confesse ses péchés.
3SG.M confess.3SG.PRS his sins
'He confesses his sins'.
b. Il se confesse (de ses péchés). 3SG.M ANTIP confess.3SG.PRS PREP his sins
'He confesses his sins'.
c. Il se confesse.
3SG.M ANTIP confess.3SG.PRS
'He confesses'.


In (24), the oblique phrase (de ses péchés) can be dropped from the surface structure. This is shown in (24b) with (24c) respectively and corresponds to Dixon \& Aikhenvald's (1997, 74; 2000, 9) general observation on antipassives according to which the underlying $\mathrm{O}$ argument [ $=$ the $\mathrm{P}$ ] goes into a peripheral function, being marked by a non-core case, adposition, etc.; this argument can be omitted, although there is always the option of including it.' One can speculate that the possibility to omit the oblique argument is favored by the fact that the lexical meaning of the verb 'confess' considerably restricts the range of possible arguments. Reserved to the religious context, the verb potentially implies one type of argument i.e. 'sin'. The omission of the oblique de ses péchés is related to detopicalization of this constituent. This consequently shifts a reader's attention to the agent and to the action he/she performs (on oblique omission see also Dom et al. 2015, 376 and (Janic 2021, §5.1.3). Example (25) shows the opposite situation, where the $\mathrm{P}$ must be obligatorily expressed in the antipassive.

(25) French (Indo-European; Janic 2016, 205)

\begin{tabular}{lllllll} 
a. Les & étudiants & \multicolumn{2}{c}{ attaquent } & les & révisions & dès \\
DEF.PL & student.PL & \multicolumn{2}{c}{ start.PRS.3PL } & DEF.PL & revision.PL & PREP \\
le & mois & de & mars. & & & \\
DEF.SG.M & month & PREP & March & & &
\end{tabular}

'The students start the revision from March'.

$\begin{array}{llllll}\text { b. Les étudiants } & \text { s' } & \text { attaquent } & \text { aux } & \text { révisions } \\ \text { DEF.PL } & \text { student.PL ANTIP start.PRS.3PL } & \text { PREP.DEF.PL } & \text { revision.PL } \\ \text { dès } & \text { le } & \text { mois de mars. } & & \\ \text { PREP } & \text { DEF.SG.M } & \text { month } & \text { PREP March } & \\ \text { 'The students start the revision from March. }\end{array}$

c. *Les étudiants s' attaquent dès le mois de mars. DEF.PL student.PL ANTIP start.PRS.3PL PREP DEF.SG.M month PREP March 'The students start the revision from March'.

When the verb attaquer 'start' is used intransitively with an oblique phrase, (25b), it lexically means 'to start something'. The omission of the peripherical argument in (25c) shifts the lexical meaning of this verb towards a literal reading 'attack oneself'. Even if such an interpretation is possible it is excluded for pragmatic reasons. In contrast, nothing comparable is observed for confesser. whether it occurs with an oblique phrase or not the meaning of the verb remains the same. This raises an important question of why the verb confesser allows the omission of an oblique phrase but not attaquer. A possible explanation is to be potentially searched for in the process of lexicalization. Janic (2016, 210-220, 2019, 79-81) reveals the extremely lexicalized nature of antipassive constructions in French, which makes it very difficult to find important 
regularities. One can speculate like with the reference to the verb 'confess' (see the discussion above). However, in order to propose convincing generalizations a more advanced investigation would be in order. For instance, the consideration of all the verbs which allow for the omission of the oblique would allow us to verify if these verbs share a common characteristic which would oppose them to those verbs which do not admit the omission of the oblique argument in the antipassive construction.

\section{Summary and conclusions}

This study has provided a general overview of antipassives in languages of the world. In the light of new data related to the form of these constructions and to their functions, the first aim of this study was to show that the notion of antipassive should be revised. I drew attention to the fact that the investigation of antipassives has been biased for decades, and I aimed to demonstrate the consequences of this for the notion of antipassive. To this end, I discussed the misleading initial trends in the analysis of antipassives, which were subsequently followed in the literature. Three aspects were taken into account: the correlation between language alignment and syntactic operations, antipassive marking, and the symmetric relationship to passive derivations. Given that the formal and functional diversity of antipassives lie at the heart of the antipassive investigation, another aim of this paper was to capture some of the variation emerging from the crosslinguistic comparison, especially in the light of new data and analysis.

Firstly, I showed that contrary to what is, or has been, commonly argued, the antipassive is not limited to a morphologically ergative type of alignment. Even if the antipassive is less visible in accusative languages and may not perform all the functions encountered in languages with deep ergativity, this by no means contradicts the existence of antipassives in languages with morphologically accusative organization. The stronger visibility of these constructions in the ergative system signalled, for instance, by a change of coding of the A argument, is not directly related to the main characteristics of the antipassive construction and should be regarded as a side-effect resulting from language specific properties. In this respect, I mentioned that in ergative languages, a transition from basic to antipassive constructions may not always affect coding properties of the A argument. Three Australian languages, Warlpiri (Pama Nyungan), Jaru (Pama Nyungan) and Gooniyandi (Bunaban) are notable exceptions.

I also discussed the notion of the antipassive marker, drawing attention to the fact that it has received different treatments in the literature, which has consequently led to the false interpretation that antipassive constructions not only must contain an antipassive marker but also that it should be monosemous. This position has been adopted by Palmer (1994) and LaPolla (2000). Further, perhaps because the term 'antipassive' was first introduced in so-called ergative languages, I argued that this presumably pushed various scholars to conclude that only such languages have 
specialized antipassivizers. To refute this opinion, I referred to studies by (Janic 2016; Polinsky 2005; Creissels 2021) who convincingly showed that accusative languages may also have dedicated antipassivizers. To this end, I mentioned the recent findings from Circassian languages and from Dinka (Nilotic), in which the antipassive construction is not derived by an explicit verbal marker as initially suggested by Silverstein (1976) but may also result from a phonological change in the verbal stem. At a more advanced level, these two particularly clear examples call into question a commonly accepted statement that the basic and antipassive constructions stand in a markedness relationship to each other, and encourage new questions about the marking of antipassive constructions.

Finally, even if at first sight it is reasonable to propose a mirror-image relationship between antipassive and passive, a more fine-grained analysis indicates important differences that call into question this proposition. In the first place, I argued that a lack of symmetry is pronounced at the functional level and concerns the relationship between semantic and discursive roles of verbal arguments. Unlike the antipassive, the passive predicate modifies the prototypical alignment between discourse and semantic roles. I also showed that there are formal differences. While passives involve promotion (Creissels 2006,8), nothing comparable can be observed for antipassives. Finally, in contrast to antipassives, passives are not constrained to transitive verbs: I challenged this widespread observation by referring to recent data from Kuban Kabardian (Circassian) in which the antipassive can be derived from twoparticipant bivalent verbs which are syntactically intransitive. I suggested that in order to include data from Kuban Kabardian, the definition of antipassive should operate in terms of verbal valency referring to the number of arguments the verb occurs with, rather than in terms of syntactic transitivity of verbal predicates.

The second part of my study highlighted the formal and functional diversity of antipassives to give an idea of typological variations they display and to see how far these variations can go across languages. To this end, I discussed coding properties, different realizations of the $\mathrm{P}$ argument and antipassive marking. It was shown that there is a general agreement on coding properties of the antipassive construction such as flags and indexes. With regard to the different behavior of the $\mathrm{P}$ argument, beyond a mainstream view favoring omission and oblique expression, I also addressed the question of incorporation, which has not gained consensus among scholars. The main argument against the inclusion of $\mathrm{P}$ incorporation under the notion of antipassive was developed by Foley (2007), who argued that $P$ incorporation cannot be included as true antipassives because, in contrast to antipassives, $\mathrm{P}$ incorporation does not involve derivational morphology. However, this observation was simplified as it was based on the language-specific analysis of Chukchi. I showed that data taken from Oceanic languages (e.g. Hoava) convincingly contradict Foley's (2007) line of argumentation. I suggested that instead of relying on a language-particular investigation, it is more convincing to consider empirical facts. The argument for treating both types of 
constructions as different language phenomena may result from the observation that unlike antipassive verbs, complex predicates of incorporation are unable to assign a semantic role to the non-agent participant. The final parameter of variations concerned the nature of the antipassivizer. If one builds on the assumption that the antipassive marker should be a defining criterion of the antipassive, then the very nature of such a marker varies as it can be either dedicated or co-expressive.

The last point discussed in this study concerned the motivation for the different realization of the $\mathrm{P}$ argument in the antipassive construction. It was shown that while in some languages, a low degree of identifiability may lead to the suppression of this argument (e.g. Mam), in others such an argument may be realized as an oblique (e.g. Chamorro). Yet, in Kuku Yalanji, the oblique realization of the $\mathrm{P}$ argument received the interpretation of low degree of specificity. In addition to the discourse-pragmatic motivation, attention was also drawn to the semantic motivation of the antipassive. In languages like Chamorro, Chukchi or English, it was shown that the oblique expression of the $\mathrm{P}$ argument was interpreted as being partially affected. This commonly observed crosslinguistic pattern is challenged by recent findings from East Uvean (Austronesian), in which the oblique $\mathrm{P}$ argument of the antipassive is viewed as specifically and exclusively affected. Finally, in French, the different realization of the P argument in antipassive constructions seems to be driven by the process of lexicalization.

This contribution has given an overview of the relevant issues involved in antipassive constructions. Thanks to new data which have come available over the last few years, we could further the original definitions given in Silverstein 1972 and 1976 and get a better and more nuanced insight of the antipassive constructions.

\section{Abbreviations}

A agent, ABS absolutive, ACC accusative, ACT active, AOR aorist, ANTIP antipassive, ART article, ASP aspect, DAT dative, DEF definite, DEP depatientive, DS directional suffix, DYN dynamic, ERG ergative, $F$ feminine, FUT future, INCOMPL incompletive, INS instrumental, ITR iterative, LOC locative, $M$ masculine, MSD nominalization, NEG negation, NOM nominative, OBJ object, OBL oblique, PL plural, POSS possessive, PREP preposition, PRS present, PST past, REF reflexive, SBJ subject, SG singular, SPC specific article, TR transitive, 1 first person, 2 second person, 3 third person.

\section{References}

Aldridge, Edith. 2012. "Antipassive and Ergativity in Tagalog". Lingua122(3): 192-203.

Arkadiev, Peter \& Alexander Letuchiy. 2021. "Indirect antipassive in Circassian". In Antipassive: Typology, Diachrony, and Related Constructions, edited by Katarzyna Janic \& Alena Witzlack-Makarevich, Amsterdam: John Benjamins Publishing Company (forthcoming). 
Babby, Leonard H. 1975. "A Transformational Analysis of Transitive-Sja Verbs in Russian". Lingua35(3): 297-332.

Bickel, Balthasar. 2011. "Multivariate typology and field linguistics: a case study on detransitivization in Kiranti (Sino-Tibetan)". In Proceedings of Conference on Language Documentation and Linguistic Theory 3, vol. 3, edited by Peter Austin K., Oliver Bond, Lutz Marten \& David Nathan, 1-11. SOAS University of London.

Blevins, James P. 2003. "Impersonals and Passive". Linguistics39(3): 473-520.

Blight, Charles Blight. 2004. Head Movement, Passive and Antipassive in English. University of Texas. PhD Dissertation.

Bok-Bennema, Reineke. 1991. Case and Agreement in Inuit. Berlin: Foris Publications.

Bostoen, Koen, Sebastian Dom \& Guillaume Segerer. 2015. "The antipassive in Bantu". Linguistics 53(4): 731-772.

Brecht, Richard D. \& James, Levine S. 1985. "Conditions on Voice Marking in Russian". In Issues in Russian morphosyntax (UCLA Slavic Studies 10), edited by Michael S. Flier \& Richard D. Brecht, 118-137. Columbus: Slavica Publishers.

Bricker, Victoria. 1978. "Wh-questions, relativization and clefting in Yucatec Maya". In Papers in Mayan linguistics, edited by Laura Martin, 109-139. Columbia: Lucas Brothers.

Bril, Isabelle. 2005. "Semantic and Functional Diversification of Reciprocal and Middle Prefixes in New Caledonian and Other Austronesian Languages". Linguistic Typology 9(1): $25-76$.

Charney, Jean Ormsbee. 1993. A grammar of Comanche. Lincoln: University of Nebraska Press.

Comrie, Bernard. 1977. "In defense of spontaneous demotion: the impersonal passive". In Grammatical relations (Syntax and Semantics 8) edited by Peter Cole \& Jerrold M. Sadock, 47-58. New York: Academic Press.

Comrie, Bernard. 1978. "Ergativity". In Syntactic typology: studies in the phenomenology of language, edited by Winfred P. Lehmann, 329-394. Austin: University of Texas Press.

Comrie, Bernard, Diana Forker, Madzhid Khalilov, Zaira Khalilova \& Helma Van den Berg. 2015. "Antipassives in Tsez and Beyond". Abstract presented at the Diversity Linguistics: Retrospect and Prospect, MPI-EVA, Leipzig.

Comrie, Bernard, Diana Forker, Zaira Khalilova \& Helma Van den Berg. 2021. "Antipassives in Nakh-Daghestanian languages: Exploring the margins of a construction". In Antipassive: Typology, Diachrony, and Related Constructions, edited by Katarzyna Janic \& Alena Witzlack-Makarevich, Amsterdam: John Benjamins Publishing Company (forthcoming).

Comrie, Bernard, Madzhid Khalilov \& Zaira Khalilova. 2015. "Valency and valency classes in Bezhta". In Valency Classes in the World's Languages, edited by Andrej L. Malchukov \& Bernard Comrie, vol.1, 541-540. Berlin: De Gruyter Mouton. 
Cooreman, Ann. 1988. "The Antipassive in Chamorro: Variations on the Theme of Transitivity". In Passive and Voice edited by Masayoshi Shibatani, 561-593. Amsterdam: John Benjamins Publishing Company.

Cooreman, Ann. 1994. "A Functional Typology of Antipassives". In Voice: Form and Function, edited by Barbara A. Fox \& Paul J. Hopper, 49-88. Amsterdam: John Benjamins Publishing Company.

Creissels, Denis. 2006. Syntaxe générale: une introduction typologique. 2, La phrase. Paris: Hermès Science.

Creissels, Denis. 2012. "The origin of antipassive markers in West Mande languages". Presented at the 45th Annual Meeting of the Societas Linguistica Europaea, Stockholm.

Creissels, Denis. 2015. "Valency properties of Mandinka verbs". In Valency Classes in the World's Languages, edited by Andrej L. Malchukov \& Bernard Comrie, 221-259. Berlin: De Gruyter Mouton.

Creissels, Denis. 2016. "Transitivity, valency and voice". Porquerolles: European Summer School in Linguistic Typology, ms.

Creissels, Denis. 2021." Antipassive derivation in Soninke (West Mande)". In Antipassive: Typology, Diachrony, and Related Constructions, edited by Katarzyna Janic \& Alena Witzlack-Makarevich. Amsterdam: John Benjamins Publishing Company (forthcoming).

Croft, William. 2012. Verbs: Aspect and Causal Structure. Oxford: Oxford University Press.

Davis, Karen. 2003. A grammar of the Hoava language, Western Solomons. Canberra: Pacific Linguistics, Research School of Pacific and Asian Studies, Australian National University.

De Rijk, Rudolf P.G. 2002. "L’antipassif Basque et l'hypothèse de Levin". Revue D'études Basques 7: 295-312.

DeLancey, Scott. 2004. "The blue bird of ergativity". In Ergativity in Amazonia (3) edited by Francesc Queixalós, 1-37. Paris: Celia.

Dixon, R.M.W. (ed.). 1976. Grammatical Categories in Australian Languages. Canberra: Australian Institute of Aboriginal Studies; Humanities Press.

Dixon, R.M.W.1988. A grammar of Boumaa Fijian. Chicago: University of Chicago Press.

Dixon, R.M.W.1994. Ergativity. Cambridge: Cambridge University Press.

Dixon, R.M.W. 2012. Basic Linguistic Theory Volume 3: Further Grammatical Topics. Oxford: Oxford University Press.

Dixon, R.M.W. \& Aleksandra Y. Aikhenvald. 1997. "A Typology of Argument-Determined Constructions". In Essays on language function and language type: dedicated to T. Givón, edited by Joan L. Bybee, John Haiman \& Sandra Thompson, 71-113. Amsterdam: John Benjamins Publishing Company.

Dixon, R.M.W. \& Alexandra Y. Aikhenvald (eds.). 2000. Changing Valency: Case Study in Transitivity. Cambridge: Cambridge University Press. 
Dixon, Robert M.W. 1972. The Dyirbal language of North Queensland. London: Cambridge University Press.

Dom, Sebastian, Guillaume Segerer \& Koen Bostoen. 2015. "Antipassive/associative polysemy in Cilubà (Bantu, L31a): A plurality of relations analysis". Studies in Language39(2): 354-385.

England, Nora C. 1983. A grammar of Mam, a Mayan language. Austin: University of Texas Press.

England, Nora C. 1988. "Mam Voice". In Passive and voice, edited by Masayoshi Shibatani, 525-545. Amsterdam: John Benjamins Publishing Company.

Farrell, Patrick. 2005. Grammatical relations. Oxford: Oxford University Press.

Foley, William A. 2007. "A typology of information packaging in the clause". In Language Typology and Syntactic Description: Clause Structure edited by Timothy Shopen, vol. 1, 362-446. Cambridge: Cambridge University Press.

Foley, William A. \& Robert D. Van Valin. 1984. Functional Syntax and Universal Grammar. Cambridge: Cambridge University Press.

Geniušienė, Emma. 1987. The typology of reflexives. Berlin: De Gruyter Mouton.

Gerdts, Donna B. 1988. Object and absolutive in Halkomelem Salish. New York: Garland Publishing.

Givón, Talmy. 2001. Functional-Typological introduction. Vol. 2. Amsterdam: John Benjamins Publishing Company.

Grinevald-Craig, Colette. 1979. "The antipassive and Jacaltec". (Ed.) Laura Martin. Papers in Mayan Linguistics , 139-165.

Hale, Ken. 1973a. "Person marking in Walbiri". In A Festschrift for Morris Halle, edited by S.R. Anderson and P. Kiparky, 308-344. New York: Holt, Rinehart \& Winston.

Haspelmath, M. 1993. A Grammar of Lezgian. Berlin: Mouton de Gruyter.

Haspelmath, Martin \& Thomas Müller-Bardey. 2004. "Valence Change". In Morphologie: ein internationales Handbuch zur Flexion und Wortbildung, edited by G.E. Booij, Christian Lehmann \& Joachim Mugdan, 1130-1145. Berlin: De Gruyter Mouton.

Heath, Jeffrey.1976. "Antipassivization: A Functional Typology". In Proceedings of the Second Annual Meeting of Berkeley Linguistics Society, edited by Henry Thompson \& Kenneth Whistler, 202-211. Berkeley: Berkeley Linguistics Society.

Heath, Jeffrey. 1999. A Grammar of Koyraboro (koroboro) Senni: The Songhay of Gao, Mali. Köln: Rüdiger Köppe Verlag.

Heaton, Raina. 2017. A typology of antipassives, with speciation reference to Mayan. Manoa: University of Hawaii. Unpublished PhD dissertation.

Herslund, Michael. 1997. "Passive and Antipassive in a Functional Description of French Reflexive Verbs". Journal of Linguistics. Hermes 19. 75-92.

Hopper, Paul J. \& Sandra A. Thompson. 1980. "Transitivity in Grammar and Discourse". Language 56(2). 251-299. 
Israeli, Alina. 1997. Semantics and Pragmatics of the "Reflexive" Verbs in Russian. München: Verlag Otto Sagner.

Jacques, Guillaume. 2014. "Denominal Affixes as Sources of Antipassive Markers in Japhug Rgyalrong". Lingua 138.1-22.

Jacques, Guillaume. 2021. "Antipassive derivations in Sino-Tibetan/Trans-Himalayan and their sources". In Antipassive: Typology, Diachrony, and Related Constructions, edited by Katarzyna Janic \& Alena Witzlack-Makarevich, Amsterdam: John Benjamins Publishing Company (forthcoming).

Janic, Katarzyna. 2015. The antipassive in accusative languages. Plenary talk given at the $11^{\text {th }}$ Conference of the Association for Linguistic Typology, August 1, Albuquerque (NM).

Janic, Katarzyna. 2016. L’antipassif dans les langues accusatives. Brussels: Peter Lang.

Janic, Katarzyna. 2018. "Synchronic and diachronic aspects of valency-reducing devices in Oceanic languages". In Valency-changing operations within and across languages [Thematic issue] edited by Katarzyna Janic \& Nicole Nau. Lingua Posnaniensis 58(2): 151-188.

Janic, Katarzyna. 2019. "Analyse sémantique des formes «se -verbes avec un argument oblique en français". Languages. 216(4): 71-85.

Janic, Katarzyna. 2021. "The structure of antipassive constructions from a cross-linguistic perspective". In Antipassive: Typology, Diachrony, and Related Constructions, edited by Katarzyna Janic \& Alena Witzlack-Makarevich. Amsterdam: John Benjamins Publishing Company (forthcoming).

Janic, Katarzyna \& Alena Witzlack-Makarevich. 2021a. "The multifaceted nature of antipassive constructions". In Antipassive: Typology, Diachrony, and Related Constructions, edited by Katarzyna Janic \& Alena Witzlack-Makarevich, Amsterdam: John Benjamins Publishing Company.

Janic, Katarzyna \& Alena Witzlack-Makarevich (eds.). 2021b. Antipassive: Typology, Diachrony, and Related Constructions. Amsterdam: John Benjamins Publishing Company.

Johns, Alana. 1999. "The decline of ergativity in Labrador Inuttut". Edited by Leora Bar-El, Rose-Marie Déchaine \& Charlotte Reinholtz. Papers from the Workshop on Structure and Constituency in Native American Languages. MIT Occasional Papers in Linguistics 17: 73-90.

Johns, Alana. 2006. "Ergativity and change in Inuktitut". In Ergativity: Emerging Issues, edited by Alana Johns, Diane Massam \& Juvénal Ndayiragije, 293-311. Dordrecht: Springer.

Kański, Zbigniew. 1986. Arbitrary Reference and Reflexivity: A Generative Study of the Polish Pronoun się and its English Equivalents. Katowice: Uniwersytet Śląski.

Keenan, Edward L. \& Matthew S. Dryer. 2007. "Passive in the World's Languages". In Language typology and syntactic description: clause structure, edited by Timothy Shopen, vol. 1, 325-361. Cambridge: Cambridge University Press.

Kozinsky, Isaac, Vladimir, P. Nedjalkov \& Maria S. Polinskaja. 1988. "Antipassive in Chukchee: Oblique Object, Object Incorporation, Zero Object". In Passive and Voice, edited by Shibatani Masayoshi, 651-706. Amsterdam: John Benjamins Publishing Company. 
Kulikov, Leonid. 2011. "Voice Typology". In The Oxford Handbook of Linguistic Typology, edited by Jae J. Song, 368-398. Oxford: Oxford University Press.

Kuryłowicz, Jerzy. 1949. "La Construction Ergative et le Développement Stadial du Langage". Annali della Scuola normale superiore di Pisa. Classe di lettere e filosofia 18: 84-92.

Lambrecht, Knud. 1994. Information structure and sentence form: topic, focus, and the mental representations of discourse referents. Cambridge: Cambridge University Press.

LaPolla, Randy J. 2000. "Valency-changing derivations in Dulong/Rawang". In Changing Valency: Case Study in Transitivity edited by R.M.W. Dixon \& Alexandra Aikhenvald, 282-311. Cambridge: Cambridge University Press.

Launey, Michel. 1994. Une grammaire omniprédicative: essai sur la morphosyntaxe du nahuatl classique. Paris: CNRS.

Lazard, Gilbert. 1998. Actancy. Berlin: De Gruyter Mouton.

Legendre, Géraldine \& Akimova, Tanya. 1994. "Inversion and Antipassive in Russian". In Annual Workshop on Formal Approaches to Slavic Linguistics. The MIT meeting, 1993, edited by Sergey Avrutin, Steven Franks \& Ljiljana Progovac, 286-318. Ann Arbor: Michigan Slavic Publications.

Levin, Beth. 1993. English verb classes and alternations: a preliminary investigation. Chicago: University of Chicago Press.

Liakin, Denis \& Juvénal Ndayiragije. 2000. "Les Constructions Russes en -sja". Revue québécoise de linguistique 28(1): 111-122.

Lichtenberg, Frantisek. 2008. A grammar of Toqabaqita. Vol. 42. Berlin: Mouton de Gruyter.

Lichtenberk, František. 1991. "Reciprocals and depatientives in To'aba'ita". In Currents in Pacific linguistics: papers on Austronesian languages and ethnolinguistics in honour of George W. Grace, 171-183. Canberra: Dept. of Linguistics, Research School of Pacific Studies, Australian National University.

Lichtenberk, František. 2000. "Reciprocals without reflexives". In Reciprocals: Forms and Functions, edited by Zygmunt Frajzyngier \& Traci S. Curl, 31-62. Amsterdam: John Benjamins Publishing Company.

Lichtenberk, František. 2007. "Reciprocals and related meanings in To'aba'ita". In Reciprocal Constructions edited by Vladimir P. Nedjalkov, 1547-1574. Amsterdam: John Benjamins Publishing Company.

Malchukov, Andrej. 2017. "Markedness effects in applicative formation: Theoretical and typological perspectives". In Verb valency changes: theoretical and typological perspectives, edited by Albert Alvarez González \& Ia Navarro, 1-29. Amsterdam: John Benjamins Publishing Company.

Malchukov, Andrej L. 2015. "Valency classes and alternations: parameters of variation". In Valency Classes in the World's Languages edited by Andrej L. Malchukov \& Bernard Comrie, vol.1, 73-130. Berlin: De Gruyter Mouton. 
Masullo, Pascual Jose. 1992. "Antipassive constructions in Spanish". In Romance languages and modern linguistic theory: papers from the 20th Linguistic Symposium on Romance Languages (LSRL XX), Ottawa, 10-14 April 1990, edited by Paul Hirschbühler \& E.F.K. Koerner, 175-193. Amsterdam: John Benjamins Publishing Company.

Medová, Lucie. 2009. Reflexive Clitics in the Slavic and Romance Languages. A Comparative View from an Antipassive Perspective. Princeton University. PhD Dissertation.

Mejias-Bikandi, Errapel. 1999. "Unaccusative and Antipassive Constructions in Basque and Spanish". In Grammatical analyses in Basque and Romance linguistics: papers in honor of Mario Saltarelli, edited by Jon Franco, Alazne Landa, Juan Martín \& Mario Saltarelli, 165-177. Amsterdam: John Benjamins Publishing Company.

Mithun, Marianne. 1984. "The evolution of noun incorporation." Language 60(4): 847-894.

Mithun, Marianne. 2021. "Antipassive Propensities and Alignment". In Antipassive: Typology, Diachrony, and Related Constructions, edited by Katarzyna Janic \& Alena Witzlack-Makarevich. Amsterdam: John Benjamins Publishing Company (forthcoming).

Moyse-Faurie, Claire. 2021. "Antipassive constructions in Oceanic languages". In Antipassive: Typology, Diachrony, and Related Constructions, edited by Katarzyna Janic \& Alena Witzlack-Makarevich. Amsterdam: John Benjamins Publishing Company (forthcoming).

Mroczyńska, Katarzyna. 2017. "Realizations of antipassive-like structures in English and Polish". In Norm and anomaly in language, literature, and culture, edited by Jarosław Wiliński \& Joanna Stolarek, 61-73. Frankfurt am Main: Peter Lang Edition.

Mroczyńska, Katarzyna. 2018. Realizations of antipassive-like structures in Polish and English. Lublin: Wydawnictwo KUL.

Mroczyńska, Katarzyna. 2019. "Antipassive-like features in English and Polish". In Valency in verbs and verb-related structures, edited by Anna Malicka-Kleparska \& Maria Bloch-Trojnar, 195-211. Berlin: Peter Lang.

Ndayiragije, Juvénal. 2006. "The Ergativity Parameter: A View from Antipassive". In Ergativity: Emerging Issues, edited by Alana Johns, Diane Massam \& Juvenal Ndayiragije, 271-292. Dordrecht: Springer.

Noonan, Michael. 1992. A Grammar of Lango. Berlin: De Gruyter Mouton.

Nouguier Voisin, Sylvie. 2005. "Antipassif et Langues Accusatives". In Linguistique typologique, edited by Gilbert Lazard \& Claire Moyse-Faurie, 193-206. Villeneuve d'Ascq: Presses Universitaires du Septentrion.

Palmer, Frank R. 1994. Grammatical Roles and Relations. Cambridge: Cambridge University Press.

Patz, Elizabeth. 2002. A grammar of the Kuku Yulanji language of North Queensland. Canberra: Pacific Linguistics.

Polinsky, Maria. 2005. "Antipassive Constructions". In The World Atlas of Language Structures, edited by Martin Haspelmath, Matthew S. Dryer, David Gil \& Bernard Comrie, 438-439. New York: Oxford University Press. 
Polinsky, Maria. 2017. "Antipassive". In The Oxford handbook of ergativity, edited by Jessica Coon, Diane Massam \& Lisa deMena Travis, 308-331. Oxford: Oxford University Press.

Pustet, Regina \& David S. Rood. 2008. "Argument dereferentialization in Lakota". In The typology of semantic alignment, edited by Mark Donohue \& Søren Wichmann, 334-356. Oxford: Oxford University Press.

Renaudier, Marie. 2012. Dérivation et valence en sereer. Variété de Mar Lodj (Sénégal). Lyon: Université Lumière Lyon 2. Unpublished PhD dissertation.

Rivero, María Luisa. 2000. "Impersonal SIĘ in Polish: A Simplex Expression Anaphor". Journal of Slavic Linguistics 8(2): 199-237.

Rivero, María Luisa \& Milena Sheppard. 2003. "Indefinite Reflexive Clitics in Slavic: Polish and Slovenian". Natural Language \& Linguistic Theory 21(1): 89-155.

Rude, Noel.1988."Ergative, Passive, and Antipassive in Nez Perce: A Discourse Perspective". In Passive and Voice, edited by Masayoshi Shibatani, 547-560. Amsterdam: John Benjamins Publishing Company.

Ruzicka, Rudolf. 1992. "Slavic and Italian Impersonal Constructions with Reflexive Clitics". In Fügungspotenzen: Zum 60. Geburtstag Von Manfred Bierwisch. edited by Ilse Zimmermann, Anatoli Strigin \& Manfred Bierwisch, 133-161. Berlin: Akademie Verlag.

Sansò, Andrea. 2017. "Where do antipassive constructions come from? A study in diachronic typology". Diachronica34:175-218.

Say, Sergey. 2008. K tipologii antipassivnyx konstrukcij: Semantika, pragmatika, sintaksis [Towards a typology of anti-passive constructions: Semantics, pragmatics, syntax]. St. Petersburg: Institute of Linguistic Studies Unpublished PhD dissertation.

Say, Sergey. 2021." Antipassive and the lexical meaning of verbs". In Antipassive: Typology, Diachrony, and Related Constructions, edited by Katarzyna Janic \& Alena Witzlack-Makarevich, Amsterdam: John Benjamins Publishing Company (forthcoming).

Schlie, Ginny.1983. Individuation and Topicality as Indices of Transitivity: Degrees of Passive in Kara. Ukarumpa, Papua New Guinea: Summer Institute of Linguistics, ms. http://www.sil.org/pacific/png/abstract.asp?id=928474560366.

Schröder, Helga. 2015. "Alignment systems and passive-antipassive distribution in Nilotic languages". Journal of Language and Linguistics 4: 42-81.

Seržant, Ilja A., Katarzyna Janic, Oneg Ben Dror \& Darja Dermaku-Appelganz. 2021. Typology of coding patterns and frequency effects of antipassives. Studies in Language (forthcoming).

Shibatani, Masayoshi. 2009. "Case and Voice: Case in Derived Constructions". In The Oxford Handbook of Case (Oxford Handbooks in Linguistics) edited by Andrej L. Malchukov \& Andrew Spencer, 323-338. Oxford: Oxford University Press.

Silverstein, Michael. 1972. "Chinook Jargon: Language Contact and the Problem of Multilevel Generative Systems, part I". Language 48(2): 378-406. 
Silverstein, Michael. 1976. "Hierarchy of Features and Ergativity". In Grammatical Categories in Australian Languages, edited by R. M. W. Dixon, 112-171. Canberra: Australian Institute of Aboriginal Studies; Humanities Press.

Spreng, Bettina. 2005. "Third person arguments in Inuktitut". In Proceedings of the Workshop on the Structure and Constituency of the Languages of the Americas 10, vol. 17, edited by Solveiga Armoskaite \& James J. Thompson, 215-225. Vancouver, BC: UBC Working Papers in Linguistics.

Tsunoda, Tasaku. 1981. The Djaru language of Kimberley, Western Australia Canberra: Pacific Linguistics.

Tsunoda, Tasaku. 1988. "Antipassive in Warrungu and other Australian Languages". In Passive and voice, edited by Masayoshi Shibatani, 595-649. Amsterdam: John Benjamins Publishing Company.

Tuggy, David. 2010. "Function Becomes Meaning: The Case of Nawatl "Tla-". In A Mosaic of languages and cultures: studies celebrating the career of Karl J. Franklin (19), edited by Kenneth A. McElhanon \& Gerard P. Reesink, 310-326. SIL Electronic Publications.

Van Valin, Robert D. 1980. "On the Distribution of Passive and Antipassive Constructions in Universal Grammar". Lingua 50(4): 303-327.

Vigus, Meagan. 2018. "Antipassive constructions: Correlations of form and function across languages". Linguistic Typology 22(3):339-384.

Zúñiga, Fernando \& Seppo Kittilä. 2019. Grammatical voice. Cambridge: Cambridge University Press. 